\title{
Feature binding in visual short term memory: A General Recognition Theory analysis
}

\author{
Daniel Fitousi ${ }^{1}$
}

Published online: 23 May 2017

(C) Psychonomic Society, Inc. 2017

\begin{abstract}
Creating and maintaining accurate bindings of elementary features (e.g., color and shape) in visual short-term memory (VSTM) is fundamental for veridical perception. How are low-level features bound in memory? The present work harnessed a multivariate model of perception - the General Recognition Theory (GRT) - to unravel the internal representations underlying feature binding in VSTM. On each trial, preview and target colored shapes were presented in succession, appearing in either repeated or altered spatial locations. Participants gave two same/different responses: one with respect to color and one with respect to shape. Converging GRT analyses on the accuracy confusion matrices provided substantial evidence for binding in the form of violations of perceptual independence at the level of the individual stimulus, such that positive correlations were obtained when both features repeated or alternated together, while negative correlations were obtained when one feature repeated and the other alternated. This "cloverleaf" GRT pattern of binding was similar whether the spatial location of the preview and target repeated or altered. The current results are consistent with: (a) the discrete memory "slots" model of VSTM, and (b) the notion that spatial location is not necessary for the formation of "object files." The GRT approach presented here offers a viable quantitative model for testing various questions regarding feature binding in VSTM.
\end{abstract}

Keywords Visual short-term memory $\cdot$ Feature binding

Electronic supplementary material The online version of this article (doi:10.3758/s13423-017-1303-y) contains supplementary material, which is available to authorized users.

Daniel Fitousi

danielfi@ariel.ac.il

1 Department of Behavioral Science, Ariel University, Ariel, Israel

\section{Introduction}

The objects of perception are multidimensional, yet they are perceived as unitary wholes. Looking at a plate of fruit, we integrate the red color of the apple with its round shape, and the yellow color of the banana with its curved shape. Fortunately, we do not mix the colors or the shapes of the two objects. This accurate and rapid binding documents a remarkable achievement of our visual system. The reason is that although features (e.g., color, shape, or size) are encoded in a distributed manner across different locations in the brain (Hubel \& Wiesel, 1977), they are integrated into their veridical configuration. The computational challenge involved in such an endeavor has been often dubbed the binding problem (Singer \& Gray, 1995; Treisman, 1996; von der Malsburg, 1999; see also Fitousi, 2017a, b). A major question in the study of binding concerns the nature of the internal representation underlying the bound features (Luck \& Vogel, 1997), as well as the role of attention to location in generating these bindings (Wheeler \& Treisman, 2002). The present study harnessed a powerful methodology known as the General Recognition Theory (GRT; Ashby \& Townsend, 1986) to address these questions.

Evidence for feature binding in visual memory comes from various sources. Kahneman, Treisman, and Gibbs (1992) have used a preview task in which a letter appeared in a prime display, and then the same letter or different letters were presented in a probe display. Naming latencies for the probe letter were faster if the letter's identity was repeated within the same location/object. This result was taken as evidence for the creation of "object files" - temporary, episodic structures that are capable of overcoming spatiotemporal discontinuities. Using a similar preview task, Hommel (1998) asked observers to judge the color of a probe letter preceded by a preview letter. The color, shape, or location of the probe letter could repeat or 
alternate from the preview letter. Hommel found that repeating two given features (e.g., a red " $x$ " followed by a red " $x$ ") or alternating them altogether (e.g., a red " $x$ " followed by a green "o") yielded superior performance to that observed in conditions in which one of the features was repeated and the other was alternated (e.g., a red "x" followed by a red "o"). The pattern - partial-repetition costs (Hommel, 1998; Fitousi, $2017 \mathrm{a}, \mathrm{b}$ ) - was taken as evidence for the creation of "object files." According to Hommel, "object files" do not consist of the entire list of features, but rather include a set of pairwise bindings (e.g., shape + color, shape + location). Partial repetition costs may reflect the difficulty of retrieving an "object file" when one of its features overlaps with a previously seen “object file." According to Hommel (1998), attention to location is not necessary for binding, because partial repetition costs are found even when the probe and preview letters appear in different spatial locations.

Another source of evidence for the presence of feature bindings in visual short-term memory (VSTM) comes from a change-detection paradigm (Luck \& Vogel, 1997; Wheeler \& Treisman, 2002), in which observers indicate whether a display consisting of several colored shapes is the "same" or "different" from a preview display. Binding in this paradigm is often measured by comparing levels of accuracy for single feature (e.g., shape) and conjunctions (e.g., color and shape) (Allen, Baddeley, \& Hitch, 2006).

In most of the reviewed paradigms (Hommel, 1998; Kahneman et al., 1992; Makovski \& Jiang, 2009; Luck \& Vogel, 1997) the internal representation underlying the bound features is not well specified. Inferences regarding feature binding are made based on comparisons of performance levels (i.e., reaction time (RT), accuracy) across experimental conditions (but see Ashby, Prinzmetal, Ivry \& Maddox, 1996; Bays et al., 2011). Note that performance differences might or might not reflect a true binding process. There is always the possibility that the observed differences were generated by differences in task difficulty, or by decisional rather than perceptual influences (Green \& Swets, 1966). Arguably, such factors are only remotely, if at all, related to binding. What is needed is a model that is capable of defining a priori and quantitatively the internal representations underlying feature bindings. This model should also be capable of dissociating perceptual and decisional factors. With such a model at hand, predictions can be made and tested with increased confidence that dependent variables truly reflect the presence or absence of binding. Such a model is introduced next.

\section{General Recognition Theory (GRT)}

The GRT (Ashby \& Townsend, 1986) is one of the most powerful tools available for modeling featural interaction.
It has been applied successfully to numerous research questions (see e.g., Algom, 2016; Algom \& Fitousi, 2016; Silbert \& Hawkins, 2016). The GRT is a twostage model of encoding and response selection. It is often considered to be a multidimensional extension of signal detection theory (SDT; Green \& Swets, 1966). A fundamental assumption in GRT is that perception is noisy, and consequently leads to random variability in the encoding of features. The noisy perception implies that encoding of each stimulus (a conjunction of two features) engenders stochastic trial-by trial perceptual effect. The effect for a particular stimulus $A_{i} B_{j}$ is represented as a joint density function $f_{A_{i} B_{j}}(x, y)$. A $2 \times 2$ GRT model with four stimuli leads to a perceptual space with four multidimensional distributions. When cut horizontally at a fixed probability level, four equal-likelihood contours are created. Observers assign a decisional bound with each perceptual region, and partition the perceptual space into four response regions (see Fig. 1).

\section{GRT and binding}

Consider the following change-detection paradigm. On each trial, a colored letter is presented (i.e., preview display), disappears, and then after a long enough interval that allows VSTM to operate, is followed by another letter (i.e., target display) (Fig. 2). The target's color and/or shape and/or location can either repeat or alternate from the preview (as in Hommel, 1998). Observers are asked to indicate whether the target and preview letter were same or different with respect to: (a) shape and (b) color. Four types of stimuli/responses are thus possible in such a setting: (1) same shape, same color, (2) same shape, different color, (3) different shape, same color, and (4) different shape, different color. With a considerable number of trials, confusion matrices are generated, to which GRT analyses for change-detection task are applicable (Wenger \& Ingvalson, 2002). ${ }^{1}$

Feature binding in GRT may reflect one or several types of deviations from independence between the encoded features (shape and color). A similar set of assumptions regarding uncertainty in perception and deviance from independence as markers of binding has been adopted by Ashby et al. (1996) in a stochastic model of illusory conjunction. That model is closely related to the GRT approach advanced here. In the GRT, there are three ways by which independence may hold or fail.

\footnotetext{
$\overline{1}$ Thomas (1996) has developed a GRT extension for a same/different task in which only a single response is given with respect to a multidimensional stimulus. But this development does not apply to the current task because here two responses are generated by the observer.
} 


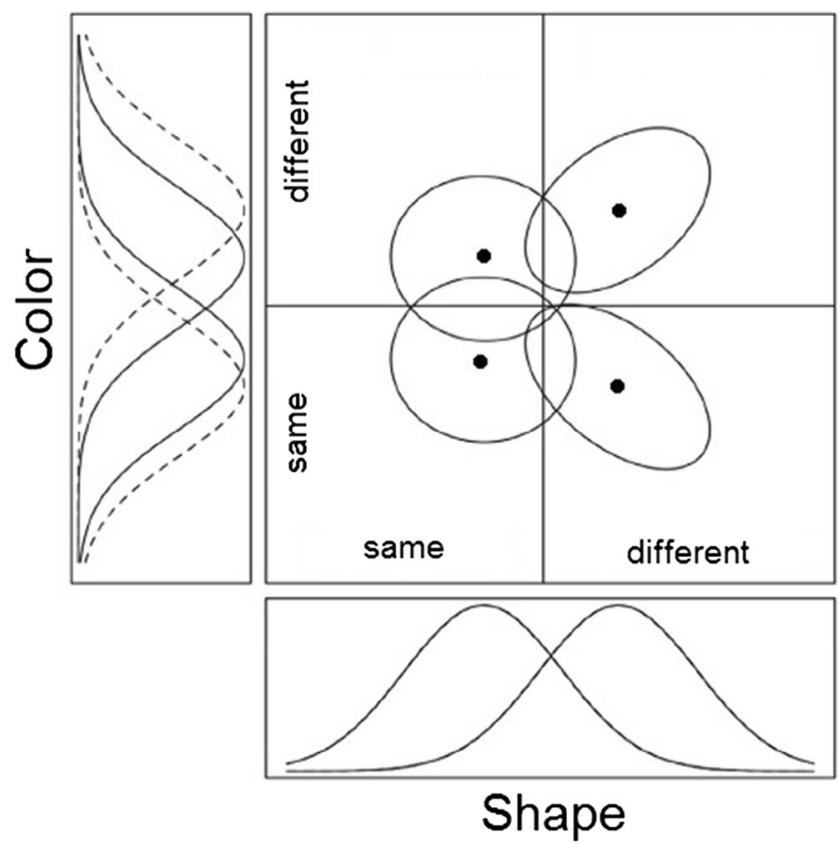

Fig. 1 An example of General Recognition Theory space in a samedifferent task with shape and color as dimensions

These are mapped onto three ways by which binding may fail or succeed: (a) Perceptual independence occurs if and only if the perceptual effects of shape and color are stochastically independent. When perceptual independence holds (and binding fails), the equal-likelihood contours will appear as either circles or ellipses, with the major and minor axes parallel to the coordinate axes in the perceptual space. When perceptual independence is violated, the ellipses will be tilted with respect to the horizontal and vertical axes. (b) Perceptual Separability holds if and only if the marginal perception of shape (color) dimension does not vary as a function of the color (shape) levels. When perceptual separability holds on both shape and color, the
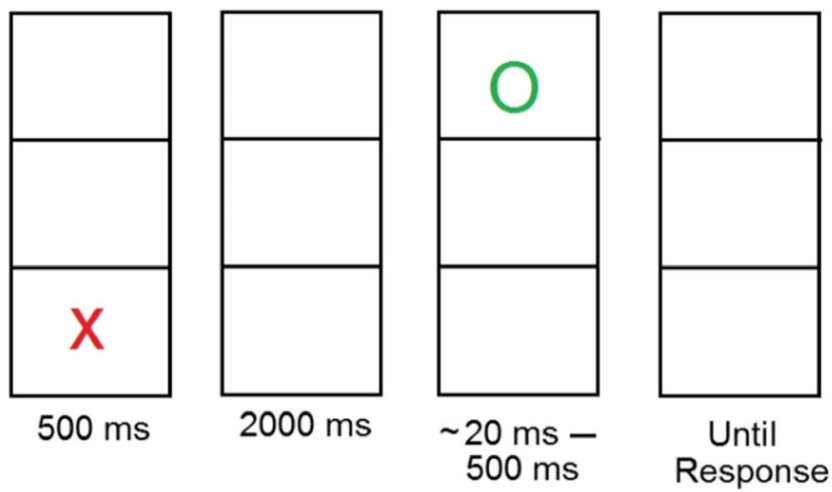

\section{Time (ms)}

Fig. 2 A typical trial in the experiment centroids of the equal likelihood contours take the form of a rectangle. When perceptual separability is violated (and binding occurs), the distances between the distributions for shape (color) are not equal across levels (e.g., same vs. different) of color (shape). (c) Decisional Separability holds if and only if the decision bound for shape (color) remains invariant across levels color (shape). Decisional separability is violated when the decision bound for shape (color) varies at the levels of color (shape).

Theoretical notions of binding (Ashby et al., 1996; Bays et al., 2011; Treisman \& Gelade, 1980; Treisman $\&$ Schmidt, 1982) have often assumed that binding involves some degree of interactive processing between features. If the features are not bound together, then they should not exhibit any form of interaction and appear as strictly independent. Thus, any violation of one of the three constructs of GRT that signals independence might serve as an indicator of binding.

\section{Methods}

\section{Participants}

Twenty-six undergraduate students from Ariel University participated. They received course credit for their participation. All observers reported normal or corrected-tonormal vision.

\section{Stimuli}

The experiment was controlled by a desktop computer. From a viewing distance of $76 \mathrm{~cm}$ the participants saw three $3.16^{0} \times 2.7^{0}$ black square outlines arranged vertically from the top to the bottom (see Fig. 2). The letters "O" and " $\mathrm{X}$ " presented at $0.4^{0} \times 0.4^{0}$ visual angle could appear either in red or green. The stimuli set consisted therefore of: a red "O," a green "O," a red "X," or a green "X." Each stimulus could appear in the upper or lower box. Responses were made by pressing one of four keys ("V," "B," "N," "M") on the keyboard.

\section{Procedure and design}

Each experimental trial started with the presentation of the preview letter (e.g., red "O"), for $500 \mathrm{~ms}$ either on the top or bottom square. Then an empty square outline was presented for 2,000 ms, followed by a target letter. The observer was instructed to press one of four response keys according to the following: (1) "V" if both shape and color in the preview and target were "same", (2) "B" if shape was "same" and color was "different", (3) "N" if shape was "different" and color was "same", and (4) "M" 
if both were "different." Extensive practice was held prior to the experiment to guarantee that participants remembered the response mapping. Each experimental block consisted of the factorial combination of all possible levels of color (red, green), shape (x, o), location (top, bottom), and preview-target relationship (repeat, alternate). All types of stimuli were presented with equal frequency. Each block consisted of 192 trials. Participants completed three blocks, which amounted to 576 trials. Accuracy was kept at $60-70 \%$ correct using a simple staircase algorithm in which the target's presentation duration on trial $n$ was increased or decreased by $5 \mathrm{~ms}$ depending on whether the participant was correct or incorrect on trial $n-1$.

\section{Results}

Confusion matrices for conditions in which the spatial location of the preview and target letters repeated or alternated were derived separately for each of the 26 participants. All of the analyses were performed twice: once on each of the individual confusion matrices and once on the aggregate matrices. The degree of correspondence between the individualby-individual and the aggregate analyses was very high (see Supplementary Material).

Table 1 presents the aggregate confusion matrices. These were created by summing up the individual matrices. The four possible stimuli are designated as: $A_{1} B_{1}$, $A_{1} B_{2}, A_{2} B_{1}$, and $A_{2} B_{2}$, respectively, with " $A$ " referring to shape and " $\mathrm{B}$ " to color. The subscript " 1 " denotes "same" and " 2 " denotes "different." Two complementary statistical approaches to analyzing the GRT data have been used (Ashby \& Lee, 1991; Fitousi, 2014; Silbert \& Hawkins, 2016). The first method consisted of a set of nonparametric tests, originally developed by Ashby and Townsend (1986). The second method relied on fitting a set of parametric models (Ashby \& Lee, 1991; Fitousi, 2014; Thomas, 2001). Recent work on GRT (Silbert \& Thomas, 2013; Silbert \& Hawkins, 2016) has shown that

Table 1 Observed confusion tables for the aggregate

\begin{tabular}{lllllllll}
\hline \multicolumn{3}{c}{ Location repeats } & \multicolumn{5}{c}{ Location alternates } \\
\multicolumn{3}{c}{ Response } \\
\hline Stimulus & $\mathrm{a}_{1} \mathrm{~b}_{1}$ & $\mathrm{a}_{1} \mathrm{~b}_{2}$ & $\mathrm{a}_{2} \mathrm{~b}_{1}$ & $\mathrm{a}_{2} \mathrm{~b}_{2}$ & $\mathrm{a}_{1} \mathrm{~b}_{1}$ & $\mathrm{a}_{1} \mathrm{~b}_{2}$ & $\mathrm{a}_{2} \mathrm{~b}_{1}$ & $\mathrm{a}_{2} \mathrm{~b}_{2}$ \\
\hline $\mathrm{A}_{1} \mathrm{~B}_{1}$ & 1,133 & 312 & 268 & 183 & 1,167 & 295 & 246 & 174 \\
$\mathrm{~A}_{1} \mathrm{~B}_{2}$ & 251 & 1,132 & 263 & 240 & 234 & 1,104 & 283 & 271 \\
$\mathrm{~A}_{2} \mathrm{~B}_{1}$ & 369 & 333 & 973 & 207 & 293 & 307 & 964 & 204 \\
$\mathrm{~A}_{2} \mathrm{~B}_{2}$ & 236 & 363 & 206 & 1,067 & 232 & 333 & 221 & 1,112 \\
\hline $\mathrm{A}$ & & & & & & & & \\
\end{tabular}

A = Shape, B =Color, "1" = Same, "2" = Different decisional separability in Gaussian GRT models is not identifiable (but see, Soto et al., 2014). Silbert and Thomas (2016) have recommended making the simplifying assumption that decisional separability holds (see also Silbert \& Hawkins, 2016). In agreement with this recommendation, decisional separability has been assumed throughout.

\section{Nonparametric tests}

The sampling independence test (Ashby \& Townsend, 1986; Townsend, Hu, \& Ashby, 1981) confirms perceptual independence and decisional separability, which may hold or fail for each stimulus. Sampling independence holds for a given stimulus if the probability of correctly identifying a given stimulus is equal to the product of the marginal probabilities of accurately identifying the level of each component of that stimulus. In the present case, this means that the probability of correct change-detection for both color and shape in a given stimulus (e.g., same shape, same color) should be equal to the product of the probability of correct changedetection for shape AND the correct change-detection for color for this stimulus. Sampling independence in $A i B j$ holds if and only if:

$$
\begin{aligned}
& p\left(\mathrm{a}_{\mathrm{i}} \mathrm{b}_{\mathrm{j}} \mid \mathrm{A}_{\mathrm{i}} \mathrm{B}_{\mathrm{j}}\right)=p\left(\mathrm{a}_{\mathrm{i}} \mid \mathrm{A}_{\mathrm{i}} \mathrm{B}_{\mathrm{j}}\right) \times p\left(\mathrm{~b}_{\mathrm{j}} \mid \mathrm{A}_{\mathrm{i}} \mathrm{B}_{\mathrm{j}}\right) \\
& =\left[p\left(\mathrm{a}_{\mathrm{i}} \mathrm{b}_{1} \mid \mathrm{A}_{\mathrm{i}} \mathrm{B}_{\mathrm{j}}\right)+p\left(\mathrm{a}_{\mathrm{i}} \mathrm{b}_{2} \mid \mathrm{A}_{\mathrm{i}} \mathrm{B}_{\mathrm{j}}\right)\right] \times\left[p\left(\mathrm{a}_{1} \mathrm{~b}_{\mathrm{j}} \mid \mathrm{A}_{\mathrm{i}} \mathrm{B}_{\mathrm{j}}\right)\right. \\
& \quad+p\left(\mathrm{a}_{2} \mathrm{~b}_{\mathrm{j}} \mid \mathrm{A}_{\mathrm{i}} \mathrm{B}_{\mathrm{j}}\right)
\end{aligned}
$$

Failures of sampling independence imply violations of perceptual independence and/or decisional separability (see Ashby \& Townsend, 1986, Theorem 1). Because decisional separability is assumed, failure of sampling independence implicates perceptual interdependency. The sampling independence test was modeled after Thomas (2001), who proposed a compact version, using a Chisquare test. Table 2 gives the sampling independence results for each observer, in each stimulus and location condition. As can be noted, failures of sampling independence were numerous across all stimuli and conditions. These results support a failure of perceptual independence, and therefore provide positive evidence for feature binding at the level of each stimulus.

Perceptual separability can be assessed with the Marginal response invariance (MRI) test (Ashby \& Townsend, 1986; Silbert \& Thomas, 2013). MRI in a discrimination confusion matrix holds when the probability of correctly detecting a change at one level of the shape feature (e.g., 
Table 2 Chi-square values of the sampling independence tests. Significant values $(\mathrm{p}<0.05)$ are highlighted in bold type

Location repeats

Location alternates

Stimulus

\begin{tabular}{lllllllll}
\hline Obs. & $\mathrm{A}_{1} \mathrm{~B}_{1}$ & $\mathrm{~A}_{1} \mathrm{~B}_{2}$ & $\mathrm{~A}_{2} \mathrm{~B}_{1}$ & $\mathrm{~A}_{2} \mathrm{~B}_{2}$ & $\mathrm{~A}_{1} \mathrm{~B}_{1}$ & $\mathrm{~A}_{1} \mathrm{~B}_{2}$ & $\mathrm{~A}_{2} \mathrm{~B}_{1}$ & $\mathrm{~A}_{2} \mathrm{~B}_{2}$ \\
\hline 1 & $\mathbf{6 . 3 0}$ & $\mathbf{1 6 . 0 2}$ & $\mathbf{4 . 0 9}$ & 2.61 & $\mathbf{8 . 7 1}$ & $\mathbf{9 . 8 1}$ & $\mathbf{4 . 3 0}$ & $\mathbf{5 . 7 8}$ \\
2 & $\mathbf{2 1 . 8 2}$ & 0.06 & $\mathbf{1 3 . 7 8}$ & $\mathbf{2 2 . 4 9}$ & $\mathbf{1 3 . 4 2}$ & 0 & 1.83 & $\mathbf{2 7 . 4 2}$ \\
3 & $\mathbf{2 1 . 6 0}$ & 0 & $\mathbf{5 . 7 9}$ & $\mathbf{1 2 . 3 4}$ & 3.04 & 0.02 & $\mathbf{5 . 8 0}$ & $\mathbf{2 9 . 5 1}$ \\
4 & $\mathbf{4 . 1 0}$ & $\mathbf{2 4 . 7 4}$ & $\mathbf{1 0 . 8 8}$ & $\mathbf{1 1 . 0 3}$ & $\mathbf{5 . 5 9}$ & $\mathbf{1 5 . 9 5}$ & $\mathbf{6 . 5 3}$ & 1.93 \\
5 & $\mathbf{5 . 1 1}$ & $\mathbf{6 . 7 7}$ & $\mathbf{1 1 . 5 6}$ & $\mathbf{6 . 3 6}$ & 0.49 & $\mathbf{4 . 1 6}$ & $\mathbf{1 . 2 7}$ & $\mathbf{1 9 . 5 0}$ \\
6 & 0.75 & $\mathbf{6 . 5 2}$ & $\mathbf{5 . 7 0}$ & $\mathbf{7 . 2 1}$ & 0.91 & $\mathbf{6 . 5 0}$ & $\mathbf{5 . 7 5}$ & $\mathbf{1 3 . 5 2}$ \\
7 & 0.06 & 3.76 & 0.57 & $\mathbf{1 3 . 2 4}$ & 3.78 & $\mathbf{1 0 . 0 8}$ & 0.01 & $\mathbf{6 . 2 0}$ \\
8 & 0.02 & $\mathbf{2 3 . 5 8}$ & $\mathbf{2 5 . 3 8}$ & 0.08 & 2.30 & $\mathbf{3 2 . 9 5}$ & $\mathbf{3 0 . 1 7}$ & 0.28 \\
9 & $\mathbf{2 6 . 4 4}$ & 0.08 & 0.63 & $\mathbf{4 3 . 0 9}$ & $\mathbf{3 6 . 0 5}$ & 1.77 & 1.69 & $\mathbf{2 5 . 8 0}$ \\
10 & 2.79 & $\mathbf{2 7 . 9 5}$ & $\mathbf{7 . 8 9}$ & 1.85 & $\mathbf{7 . 9 9}$ & $\mathbf{1 2 . 7 2}$ & $\mathbf{8 . 3 0}$ & 0.01 \\
11 & 3.41 & 2.43 & $\mathbf{2 3 . 3 8}$ & 0.95 & $\mathbf{1 8 . 1 2}$ & $\mathbf{5 . 9 0}$ & $\mathbf{9 . 8 1}$ & 3.15 \\
12 & 2.17 & $\mathbf{2 4 . 7 5}$ & 2.85 & 1.85 & 1.94 & $\mathbf{1 4 . 7 3}$ & $\mathbf{1 5 . 2 1}$ & $\mathbf{8 . 5 7}$ \\
13 & 0.16 & $\mathbf{4 . 8 9}$ & 1.86 & 0 & $\mathbf{1 0 . 1 9}$ & $\mathbf{9 . 1 3}$ & $\mathbf{2 2 . 1 8}$ & 1.29 \\
14 & 0 & $\mathbf{3 4 . 5 7}$ & $\mathbf{2 3 . 5 8}$ & 0 & 0.27 & $\mathbf{3 1 . 6 7}$ & $\mathbf{1 0 . 2 5}$ & 0.08 \\
15 & 1.16 & $\mathbf{6 . 1 6}$ & $\mathbf{1 1 . 8 9}$ & 2.34 & 1.65 & $\mathbf{1 4 . 5 1}$ & $\mathbf{9 . 3 2}$ & 0.72 \\
16 & 0 & 1.21 & 1.87 & $\mathbf{7 . 3 8}$ & 1.81 & 0.77 & 2.95 & $\mathbf{2 7 . 3 5}$ \\
17 & 0 & 0 & 1.09 & $\mathbf{7 2 . 0 0}$ & $\mathbf{3 3 . 4 9}$ & 1.79 & 1.17 & $\mathbf{7 1 . 1 0}$ \\
18 & 1.49 & 3.08 & 0.76 & $\mathbf{5 . 7 2}$ & 1.37 & 2.91 & $\mathbf{1 1 . 0 5}$ & 3.50 \\
19 & $\mathbf{8 . 8 1}$ & 2.82 & 0.85 & $\mathbf{9 . 2 0}$ & $\mathbf{7 . 3 2}$ & $\mathbf{1 1 . 1 1}$ & $\mathbf{1 2 . 7 8}$ & $\mathbf{6 . 3 5}$ \\
20 & $\mathbf{1 5 . 6 5}$ & $\mathbf{3 2 . 0 3}$ & $\mathbf{1 1 . 5 8}$ & $\mathbf{7 . 2 3}$ & $\mathbf{1 6 . 7 9}$ & $\mathbf{2 0 . 5 4}$ & $\mathbf{6 . 7 3}$ & 1.68 \\
21 & 2.42 & $\mathbf{1 2 . 0 0}$ & 1.06 & 0.23 & 3.19 & $\mathbf{1 0 . 4 5}$ & $\mathbf{6 . 5 6}$ & 0.08 \\
22 & 2.09 & 2.69 & $\mathbf{6 . 7 7}$ & 0.01 & 1.74 & $\mathbf{2 5 . 2 2}$ & 3.76 & 0.07 \\
23 & $\mathbf{1 4 . 6 6}$ & $\mathbf{5 . 5 5}$ & 0.01 & 1.34 & $\mathbf{6 . 6 3}$ & 2.82 & $\mathbf{9 . 2 1}$ & $\mathbf{1 0 . 0 6}$ \\
24 & 0.14 & $\mathbf{1 7 . 9 4}$ & $\mathbf{1 3 . 2 9}$ & $\mathbf{4 . 6 2}$ & 0.03 & $\mathbf{2 0 . 3 0}$ & $\mathbf{5 . 4 0}$ & 1.98 \\
25 & 0 & $\mathbf{4 6 . 2 7}$ & $\mathbf{5 2 . 3 3}$ & 0 & 0.04 & $\mathbf{3 5 . 6 5}$ & $\mathbf{6 7 . 0 0}$ & 0 \\
26 & 0.01 & $\mathbf{4 3 . 1 4}$ & $\mathbf{5 9 . 0}$ & $\mathbf{5 . 6 0}$ & 2.66 & $\mathbf{4 5 . 9 8}$ & $\mathbf{4 2 . 6 2}$ & 1.90 \\
\hline & & & & & & & & \\
& & & & & & \\
& & & & &
\end{tabular}

Obs. Observer

same) does not depend on the level of color (i.e., same or different). That is:

$$
\begin{aligned}
& \mathrm{p}\left(\mathrm{a}_{\mathrm{i}} \mid \mathrm{A}_{\mathrm{i}} \mathrm{B}_{1}\right)=\mathrm{p}\left(\mathrm{a}_{\mathrm{i}} \mathrm{b}_{1} \mid \mathrm{A}_{\mathrm{i}} \mathrm{B}_{1}\right)+\mathrm{p}\left(\mathrm{a}_{\mathrm{i}} \mathrm{b}_{2} \mid \mathrm{A}_{\mathrm{i}} \mathrm{B}_{1}\right) \\
& \quad=\mathrm{p}\left(\mathrm{a}_{\mathrm{i}} \mathrm{b}_{1} \mid \mathrm{A}_{\mathrm{i}} \mathrm{B}_{2}\right)+\mathrm{p}\left(\mathrm{a}_{\mathrm{i}} \mathrm{b}_{2} \mid \mathrm{A}_{\mathrm{i}} \mathrm{B}_{2}\right)=\mathrm{p}\left(\mathrm{a}_{\mathrm{i}} \mid \mathrm{A}_{\mathrm{i}} \mathrm{B}_{2}\right)
\end{aligned}
$$

Analogous parity exists for color (B):

$$
\begin{aligned}
& p\left(b_{j} \mid A_{i} B_{j}\right)=p\left(a_{1} b_{j} \mid A_{1} B_{j}\right)+p\left(a_{2} b_{j} \mid A_{1} B_{j}\right) \\
& \quad=p\left(a_{1} b_{j} \mid A_{2} B_{j}\right)+p\left(a_{2} b_{j} \mid A_{2} B_{j}\right)=p\left(b_{j} \mid A_{2} B_{j}\right)
\end{aligned}
$$

When perceptual separability and decisional separability hold for both shape $(A)$ and color $(B)$, MRI holds. To test this hypothesis, the statistic $\mathrm{Z}$ was carefully constructed (cf. Silbert \& Hawkins, 2016; Thomas, 2001). Tables 3 and 4 present the results of these analyses. As can be noted, violations of MRI were sparse, suggesting that perceptual separability held whether the target's location repeated or alternated.

Taken together, the results of the non-parametric tests reveal one way by which features are bound in VSTM violations of perceptual independence. This entails binding at the level of the individual stimulus (e.g., red X). The next section deploys a parametric approach to validate the conclusions drawn from the non-parametric tests.

\section{Fitting parametric GRT models}

A hierarchical model fitting procedure has been performed (Ashby, \& Lee, 1991; Fitousi, 2014; Thomas, 2001) on each of the observers' confusion matrices as well as on the aggregate. In brief, it is customary to assume that the GRT distributions are bivariate-Gaussian (Ashby \& Lee, 1991; Fitousi, 2013, 2014). In a $2 \times 2$ Gaussian model, there are 12 parameters to estimate. Under the assumption of decisional separability, the decision bounds are set to $\mathrm{x}=\mathrm{y}=0$, and the marginal variances are fixed at unity (see Silbert \& Thomas, 2013 ). The hierarchical model-fitting procedure starts by defining a null model in which perceptual independence, perceptual separability, and decisional separability hold. In this null (constrained) model the number of free parameters is minimal (i.e., 4). Next, the researcher defines new models (general) with an increasing number of free parameters, and compares them to the older models. If a general model is found to have better fit than its predecessor constrained model, the researcher constructs a new model with a larger number of free parameters. The degree of fit for each model is measured with the (-) loglikelihood. General models may produce better absolute fit either due to their larger number of parameters, or due to their success at capturing real aspects of the data. To decide between two models, a likelihood ratio test has been used (Thomas, 2001). Consider two models, $M_{1}$ and $M_{2}$, where $M_{1}$ is the constrained model and $\mathrm{M}_{2}$ is the general model and their respective likelihoods $\mathrm{L}_{1}$ and $\mathrm{L}_{2}$. The null hypothesis for this test is that the constrained model is correct. The test statistic $\chi^{2}$ is defined from the likelihood ratio $\mathrm{L}_{1} / \mathrm{L}_{2}$ to be:

$\chi^{2}=-2 \ln \left(\frac{L_{1}}{L_{2}}\right)$

Also, the Akaike Information Criterion (AIC; Akaike, 1983), adjusted for the number of free parameters, has been 
Table 3 Marginal response invariance (MRI) test values. Significant $Z$ values $(p<0.05)$ are highlighted in bold type

\begin{tabular}{|c|c|c|c|c|c|c|c|c|c|c|c|c|}
\hline \multicolumn{13}{|c|}{ Stimulus } \\
\hline \multirow{2}{*}{$\frac{\text { Obs. }}{1}$} & \multicolumn{2}{|c|}{$\mathrm{A}_{1} \mathrm{~B}_{1}-\mathrm{A}_{1} \mathrm{~B}_{2}$} & \multirow{2}{*}{$\frac{z}{1.21}$} & \multicolumn{2}{|c|}{$\mathrm{A}_{2} \mathrm{~B}_{1}-\mathrm{A}_{2} \mathrm{~B}_{2}$} & \multirow{2}{*}{$\frac{\mathrm{z}}{0}$} & \multicolumn{2}{|c|}{$\mathrm{A}_{1} \mathrm{~B}_{1}-\mathrm{A}_{2} \mathrm{~B}_{1}$} & \multirow{2}{*}{$\begin{array}{l}z \\
-1.24\end{array}$} & \multicolumn{2}{|c|}{$\mathrm{A}_{1} \mathrm{~B}_{2}-\mathrm{A}_{2} \mathrm{~B}_{2}$} & \multirow{2}{*}{$\frac{z}{1.66}$} \\
\hline & 0.69 & 0.59 & & 0.27 & 0.27 & & 0.62 & 0.72 & & 0.34 & 0.22 & \\
\hline 2 & 0.75 & 0.68 & 9.97 & 0.44 & 0.32 & 1.43 & 0.67 & 0.55 & 1.43 & 0.23 & 0.16 & 1.07 \\
\hline 3 & 0.85 & 0.88 & -0.56 & 0.46 & 0.40 & 0.80 & 0.77 & 0.70 & 0.88 & 0.23 & 0.30 & -0.85 \\
\hline 4 & 0.71 & 0.72 & -0.13 & 0.29 & 0.23 & 0.21 & 0.80 & 0.72 & 1.17 & 0.37 & 0.29 & 0.96 \\
\hline 5 & 0.80 & 0.67 & 1.76 & 0.31 & 0.31 & 0 & 0.79 & 0.73 & 0.78 & 0.35 & 0.31 & 0.41 \\
\hline 6 & 0.71 & 0.79 & -1.19 & 0.41 & 0.30 & 1.32 & 0.90 & 0.87 & 0.52 & 0.32 & 0.30 & 0.40 \\
\hline 7 & 0.77 & 0.62 & 2.05 & 0.52 & 0.40 & 1.45 & 0.83 & 0.82 & 0.18 & 0.17 & 0.18 & -0.15 \\
\hline 8 & 0.71 & 0.61 & 1.31 & 0.40 & 0.28 & 1.52 & 0.78 & 0.73 & 0.78 & 0.48 & 0.35 & 1.56 \\
\hline 9 & 0.78 & 0.61 & 2.27 & 0.29 & 0.26 & 0.32 & 0.70 & 0.69 & 0.16 & 0.20 & 0.23 & -0.42 \\
\hline 10 & 0.72 & 0.65 & 0.98 & 0.33 & 0.19 & 1.92 & 0.75 & 0.62 & 1.69 & 0.29 & 0.16 & 1.82 \\
\hline 11 & 0.74 & 0.63 & 1.33 & 0.30 & 0.27 & 0.32 & 0.75 & 0.65 & 1.27 & 0.20 & 0.18 & 0.29 \\
\hline 12 & 0.75 & 0.73 & 0.28 & 0.50 & 0.31 & 2.29 & 0.74 & 0.78 & -0.66 & 0.29 & 0.24 & 0.61 \\
\hline 13 & 0.76 & 0.82 & -0.90 & 0.44 & 0.39 & 0.62 & 0.72 & 0.71 & 0.13 & 0.17 & 0.18 & -0.15 \\
\hline 14 & 0.77 & 0.79 & -0.27 & 0.39 & 0.30 & 1.15 & 0.88 & 0.72 & 2.43 & 0.22 & 0.36 & -1.74 \\
\hline 15 & 0.72 & 0.69 & 0.42 & 0.24 & 0.24 & 0 & 0.69 & 0.64 & 0.65 & 0.22 & 0.16 & 0.96 \\
\hline 16 & 0.68 & 0.75 & -0.91 & 0.28 & 0.25 & 0.43 & 0.70 & 0.67 & 0.40 & 0.18 & 0.14 & 0.78 \\
\hline 17 & 1.00 & 1.00 & 0 & 0.52 & 0.63 & -1.45 & 0.98 & 0.98 & 0 & 0.44 & 0.63 & -2.34 \\
\hline 18 & 0.69 & 0.67 & 0.18 & 0.28 & 0.27 & 0.23 & 0.73 & 0.78 & -0.67 & 0.28 & 0.10 & 2.69 \\
\hline 19 & 0.65 & 0.60 & 0.64 & 0.28 & 0.19 & 1.36 & 0.79 & 0.68 & 1.53 & 0.28 & 0.20 & 1.06 \\
\hline 20 & 0.74 & 0.65 & 1.13 & 0.38 & 0.19 & 2.46 & 0.75 & 0.75 & 0 & 0.32 & 0.28 & 0.61 \\
\hline 21 & 0.67 & 0.66 & 0.11 & 0.22 & 0.26 & -0.52 & 0.70 & 0.74 & -0.55 & 0.33 & 0.32 & 0.12 \\
\hline 22 & 0.70 & 0.78 & -1.10 & 0.31 & 0.34 & -0.29 & 0.73 & 0.72 & 0.18 & 0.23 & 0.18 & 0.82 \\
\hline 23 & 0.67 & 0.73 & -0.85 & 0.31 & 0.23 & 1.16 & 0.77 & 0.79 & -0.31 & 0.35 & 0.24 & 1.44 \\
\hline 24 & 0.82 & 0.76 & 0.92 & 0.25 & 0.32 & -1.03 & 0.72 & 0.72 & 0.05 & 0.36 & 0.27 & 1.14 \\
\hline 25 & 0.97 & 0.89 & 1.87 & 0.60 & 0.48 & 1.43 & 0.47 & 0.43 & 0.42 & 0.09 & 0 & 2.63 \\
\hline 26 & 0.88 & 0.93 & -1.03 & 0.52 & 0.56 & -0.51 & 0.35 & 0.50 & -1.76 & 0.04 & 0.05 & -0.42 \\
\hline
\end{tabular}

Obs. Observer

used to adjudicate between goodness of fit and number of free parameters.

Table 5 presents the results of the hierarchical model fitting for the aggregate in a decreasing order of fit, with the best fitting model appearing on top. It should be noted that the level of correspondence between the individualby-individual and the aggregate analyses was very high (see Supplementary Material). The two best-fitting models were: (a) a model in which perceptual independence was violated in all four stimuli and perceptual separability was violated on both dimensions, and (b) a model in which only perceptual independence was violated in all four stimuli. Note that the former model has more free parameters (12) than the latter (eight). To trade off improvement in fit against increase in number of free parameters, likelihood ratio tests were conducted (see Table 6).
All individual-by-individual likelihood ratio tests (see Supplementary Material) pointed to the model in which perceptual independence was violated in all four stimuli and perceptual separability held. The aggregate and the individual analyses were consistent with respect to this model in the location alternated condition. However, in the location repeated condition the aggregate analysis favored a model in which both perceptual independence and perceptual separability were violated. A closer look at this model showed that the degree of violation of perceptual separability was minimal. The large statistical power of the aggregate might be responsible for this deviation. So, given that both the individual-by-individual parametric and non-parametric analyses exhibited clear evidence for perceptual separability and violations of perceptual independence, the winning model was chosen to 
Table 4 Marginal response invariance (MRI) test values. Significant $Z$ values $(\mathrm{p}<0.05)$ are highlighted in bold type

Location alternates

\begin{tabular}{|c|c|c|c|c|c|c|c|c|c|c|c|c|}
\hline \multicolumn{13}{|c|}{ Stimulus } \\
\hline \multirow{2}{*}{$\frac{\text { Obs. }}{1}$} & \multicolumn{2}{|c|}{$\mathrm{A}_{1} \mathrm{~B}_{1}-\mathrm{A}_{1} \mathrm{~B}_{2}$} & \multirow{2}{*}{$\frac{z}{-0.23}$} & \multicolumn{2}{|c|}{$\mathrm{A}_{2} \mathrm{~B}_{1}-\mathrm{A}_{2} \mathrm{~B}_{2}$} & \multirow{2}{*}{$\frac{\mathrm{z}}{1.13}$} & \multicolumn{2}{|c|}{$\mathrm{A}_{1} \mathrm{~B}_{1}-\mathrm{A}_{2} \mathrm{~B}_{1}$} & \multirow{2}{*}{$\frac{z}{1.36}$} & \multicolumn{2}{|c|}{$\mathrm{A}_{1} \mathrm{~B}_{2}-\mathrm{A}_{2} \mathrm{~B}_{2}$} & \multirow{2}{*}{$\frac{z}{-1.03}$} \\
\hline & 0.73 & 0.75 & & 0.27 & 0.19 & & 0.80 & 0.71 & & 0.22 & 0.30 & \\
\hline 2 & 0.78 & 0.70 & 1.19 & 0.34 & 0.25 & 1.26 & 0.64 & 0.72 & -1.08 & 0.18 & 0.22 & -0.53 \\
\hline 3 & 0.84 & 0.79 & 0.86 & 0.54 & 0.36 & 2.07 & 0.82 & 0.70 & 1.71 & 0.31 & 0.19 & 1.71 \\
\hline 4 & 0.77 & 0.68 & 1.33 & 0.33 & 0.23 & 1.28 & 0.68 & 0.68 & 0 & 0.34 & 0.26 & 1.11 \\
\hline 5 & 0.76 & 0.69 & 1.01 & 0.36 & 0.27 & 1.19 & 0.82 & 0.72 & 1.43 & 0.24 & 0.17 & 0.92 \\
\hline 6 & 0.81 & 0.76 & 0.77 & 0.40 & 0.34 & 0.66 & 0.83 & 0.83 & 0 & 0.38 & 0.30 & 0.99 \\
\hline 7 & 0.79 & 0.70 & 1.20 & 0.40 & 0.18 & 2.93 & 0.83 & 0.68 & 2.13 & 0.19 & 0.11 & 1.42 \\
\hline 8 & 0.73 & 0.55 & 2.32 & 0.28 & 0.25 & 0.32 & 0.91 & 0.71 & 3.11 & 0.54 & 0.38 & 1.93 \\
\hline 9 & 0.79 & 0.74 & 0.69 & 0.37 & 0.32 & 0.55 & 0.73 & 0.73 & 0.11 & 0.21 & 0.32 & -1.59 \\
\hline 10 & 0.68 & 0.58 & 1.15 & 0.22 & 0.29 & -0.91 & 0.73 & 0.73 & 0 & 0.28 & 0.18 & 1.46 \\
\hline 11 & 0.67 & 0.47 & 2.36 & 0.30 & 0.12 & 2.60 & 0.68 & 0.69 & 0 & 0.20 & 0.14 & 1.02 \\
\hline 12 & 0.85 & 0.68 & 2.41 & 0.27 & 0.27 & 0 & 0.77 & 0.75 & 0.29 & 0.35 & 0.21 & 1.82 \\
\hline 13 & 0.78 & 0.75 & 0.33 & 0.30 & 0.32 & -0.15 & 0.69 & 0.76 & -0.93 & 0.17 & 0.21 & -0.63 \\
\hline 14 & 0.77 & 0.63 & 1.82 & 0.40 & 0.30 & 1.18 & 0.89 & 0.68 & 3.09 & 0.31 & 0.29 & 0.30 \\
\hline 15 & 0.68 & 0.69 & -0.19 & 0.25 & 0.21 & 0.48 & 0.68 & 0.65 & 0.34 & 0.21 & 0.23 & -0.19 \\
\hline 16 & 0.78 & 0.67 & 1.43 & 0.24 & 0.27 & -0.37 & 0.75 & 0.56 & 2.39 & 0.22 & 0.22 & 0 \\
\hline 17 & 0.98 & 0.97 & 0.52 & 0.63 & 0.48 & 1.90 & 0.97 & 0.97 & 0.53 & 0.49 & 0.49 & 0 \\
\hline 18 & 0.67 & 0.67 & 0 & 0.28 & 0.35 & -0.91 & 0.81 & 0.67 & 1.96 & 0.15 & 0.19 & -0.58 \\
\hline 19 & 0.68 & 0.56 & 1.56 & 0.23 & 0.22 & 0.11 & 0.72 & 0.76 & -0.52 & 0.28 & 0.19 & 1.19 \\
\hline 20 & 0.71 & 0.63 & 0.95 & 0.25 & 0.29 & -0.52 & 0.73 & 0.76 & -0.29 & 0.33 & 0.38 & -0.62 \\
\hline 21 & 0.73 & 0.64 & 1.14 & 0.20 & 0.18 & 0.17 & 0.81 & 0.85 & -0.60 & 0.25 & 0.27 & -0.29 \\
\hline 22 & 0.75 & 0.71 & 0.52 & 0.20 & 0.25 & -0.71 & 0.71 & 0.71 & 0.05 & 0.30 & 0.24 & 0.94 \\
\hline 23 & 0.69 & 0.71 & -0.15 & 0.20 & 0.22 & -0.34 & 0.78 & 0.69 & 1.20 & 0.30 & 0.28 & 0.26 \\
\hline 24 & 0.78 & 0.73 & 0.71 & 0.29 & 0.37 & -0.97 & 0.70 & 0.84 & -1.96 & 0.30 & 0.28 & 0.22 \\
\hline 25 & 0.95 & 0.86 & 1.98 & 0.52 & 0.50 & 0.26 & 0.60 & 0.47 & 1.50 & 0.12 & 0 & 3.11 \\
\hline 26 & 0.92 & 0.95 & -0.92 & 0.62 & 0.58 & 0.51 & 0.36 & 0.39 & -0.38 & 0.02 & 0.05 & -0.76 \\
\hline
\end{tabular}

Obs. Observer

Table 5 Summary of the fit statistics for the General Recognition Theory (GRT) hierarchical models

\begin{tabular}{|c|c|c|c|c|c|c|c|}
\hline \multicolumn{4}{|l|}{ Location repeats } & \multicolumn{4}{|c|}{ Location alternates } \\
\hline Model & Par. & $-\mathrm{InL}$ & AIC & Model & Par. & $-\mathrm{InL}$ & AIC \\
\hline$\sim \mathrm{PI} \_4, \sim \mathrm{PS}, \mathrm{DS}$ & 12 & 8,614 & 17,252 & $\sim \mathrm{PI} \_4, \sim \mathrm{PS}, \mathrm{DS}$ & 12 & 8,408 & 16,840 \\
\hline$\sim \mathrm{PI} \_4, \mathrm{PS}, \mathrm{DS}$ & 8 & 8,621 & 17,258 & PI_4, PS, DS & 8 & 8,411 & 16,838 \\
\hline$\sim P I \_1, P S, D S$ & 5 & 8,893 & 17,796 & PI, PS, DS & 8 & 8,703 & 17,422 \\
\hline $\mathrm{PI}, \sim \mathrm{PS}, \mathrm{DS}$ & 8 & 8,895 & 17,806 & PI_1, PS, DS & 5 & 8,710 & 17,430 \\
\hline PI, PS_shape, DS & 6 & 8,900 & 17,812 & PI, PS_a, DS & 6 & 8,710 & 17,432 \\
\hline PI, PS_color, DS & 6 & 8,903 & 17,818 & PI, PS_b, DS & 6 & 8,719 & 17,450 \\
\hline PI, PS, DS & 4 & 8,907 & 17,822 & PI, PS, DS & 4 & 8,726 & 17,460 \\
\hline
\end{tabular}

PI Perceptual Independence, PS Perceptual Separability, DS Decisional Separability, Par. Parameters, $\sim$ Violation, $P I_{-}$each of the four coefficient correlation parameters $(\rho)$, one per distribution, was allowed to vary freely, $P I_{-}$only one coefficient correlation parameter $(\rho)$ was allowed to vary in the four distributions 
Table 6 Likelihood ratio tests for nested models

\begin{tabular}{|c|c|c|c|c|c|c|c|c|c|}
\hline \multicolumn{5}{|l|}{ Location repeats } & \multicolumn{5}{|l|}{ Location alternates } \\
\hline Restricted & General & $x^{2}$ & $\mathrm{df}$ & $\mathrm{p}$ & Restricted & General & $x^{2}$ & $\mathrm{df}$ & $\mathrm{p}$ \\
\hline PI,PS,DS & PI, PS_a,DS & 14 & 2 & $* *$ & PI,PS,DS & PI, PS_a,DS & 32 & 2 & $* *$ \\
\hline PI,PS,DS & PI, PS_b, DS & 8 & 2 & $*$ & PI,PS,DS & PI, PS_b, DS & 14 & 2 & $* *$ \\
\hline PI, PS_shape, DS & PI, PS, DS & 10 & 2 & $*$ & PI, PS_shape,DS & PI, PS, DS & 14 & 2 & $* *$ \\
\hline PI, PPS_color, DS & $\mathrm{PI}, \sim \mathrm{PS}, \mathrm{DS}$ & 16 & 2 & $* *$ & PI, PSS_color, DS & $\mathrm{PI}, \sim \mathrm{PS}, \mathrm{DS}$ & 32 & 2 & $* *$ \\
\hline PI,PS,DS & $\sim \mathrm{PI} \_1, \mathrm{PS}, \mathrm{DS}$ & 28 & 1 & $* *$ & PI,PS,DS & $\sim \mathrm{PI} \_1, \mathrm{PS}, \mathrm{DS}$ & 32 & 1 & $* *$ \\
\hline PI,PS,DS & $\sim \mathrm{PI}{ }_{4}, \mathrm{PS}, \mathrm{DS}$ & 572 & 4 & $* *$ & PI,PS,DS & $\sim \mathrm{PI} \_4, \mathrm{PS}, \mathrm{DS}$ & 630 & 4 & $* *$ \\
\hline$\sim \mathrm{PI} \_4, \mathrm{PS}, \mathrm{DS}$ & $\sim P I \_4, \sim P S, D S$ & 14 & 4 & $*$ & $\sim \mathrm{PI}{ }_{4}, \mathrm{PS}, \mathrm{DS}$ & $\sim$ PI_4, PSS,DS & 6 & 4 & n.s \\
\hline
\end{tabular}

$\mathrm{p}<0.05^{*}, \mathrm{p}<0.01 * *, \mathrm{p}<0.001 * * *$

$H_{0}$ restricted model is correct, PI Perceptual Independence, PS Perceptual Separability, DS Decisional Separability, Par. Parameters, Violation, PI_4 each of the four coefficient correlation parameters $(\rho)$, one per distribution, was allowed to freely vary, $P I \_l$ only one coefficient correlation parameter $(\rho)$ was allowed to vary in the four distributions

be the one in which only perceptual independence is violated in all four stimuli.

Figure 3 depicts the derived GRT spaces for the winning models. The emerging pattern for most observers $(25 / 26$ in the location repeat and $24 / 26$ in the location altered condition) was found to be a "cloverleaf" (Silbert \& Thomas, 2014). In this pattern, violations of perceptual independence, as indicated by the coefficient correlation $(\rho)$, entail the presence of positive correlations between shape and color for stimuli in which the two features repeated or alternated together (e.g., the ellipses are tilted to the right), and a negative correlation for stimuli in which one feature repeats, but the other alternates (e.g., the ellipses are tilted to the left). Silbert and Thomas (2014) have recently shown that in Gaussian GRT models, optimal (Bayesian) response selection rule and mimicry of decisional separability imply either a

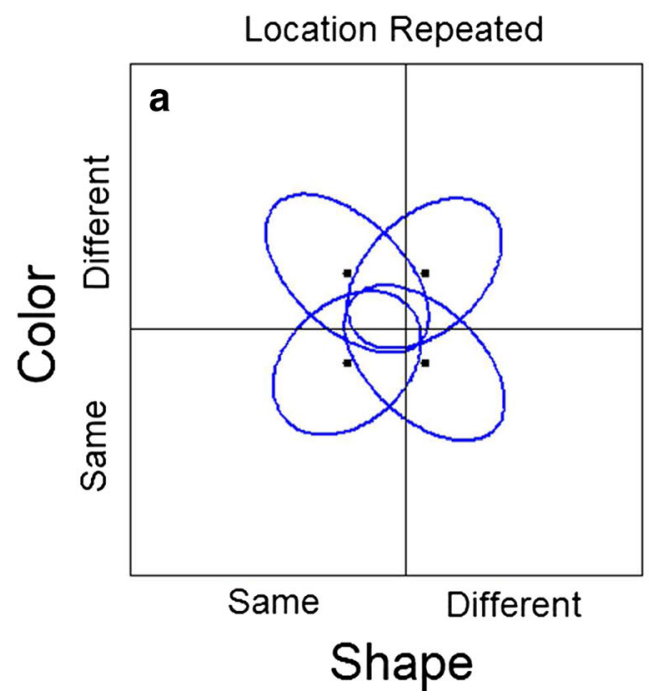

Fig. 3 Best fitting General Recognition Theory models of the hierarchical modeling fit procedure for the aggregate and for the individual data in: (a) conditions in which spatial location of the constrained rectangular arrangement of means with zero perceptual correlation or the cloverleaf pattern observed here. Thus, it might be the case that an optimal response rule in the change detection task used here mimics decisional separability due to the pattern of perceptual interactions induced by feature binding.

\section{Conclusions}

The present work harnessed a multivariate model of perception - the GRT (Ashby \& Townsend, 1986) - to investigate binding in VSTM. Converging GRT analyses provided positive evidence for binding between encoded features of shape and color. Binding was indicated by violations of perceptual independence at the level of each of the four possible stimuli,

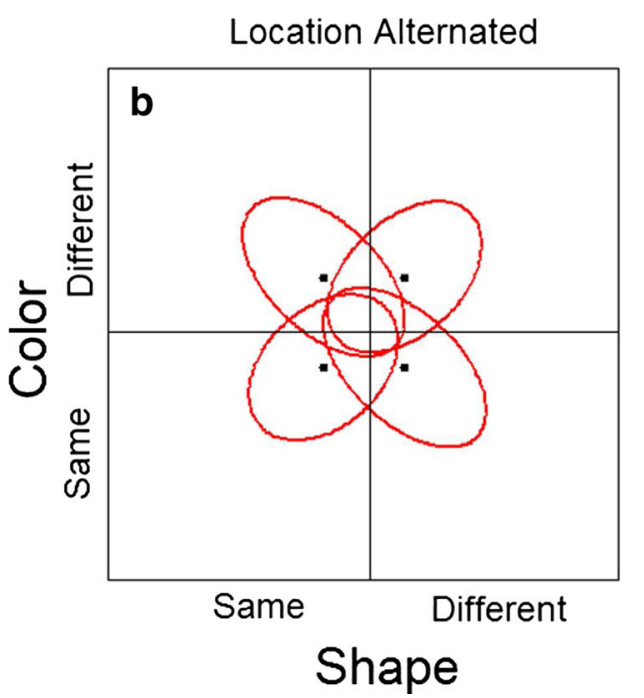

preview repeated in the target, and (b) conditions in which the spatial location alternated from preview to target 
giving rise to a cloverleaf pattern (Silbert \& Thomas, 2014). Color and shape were positively correlated when they repeated or alteranted together, but negatively correlated when only one of them repeated and the other alternated (e.g, partial rep etition). Comparable patterns have been observed whether the target and preview locations repeated or alternated. The current results are consistent with the discrete memory "slots" model of VSTM (Cowan, 2001). According to this model, each slot is storing an integrated represenatation of a single visual object. The "slots" model predicts that errors in recalling multiple features of the same object will be correlated (see also Bays et al., 2011). The results also support the notion of "object files" advanced by Hommel (1998), who has argued that spatial location is not necessary for the creation of an "object file." Finally, the current work offers a novel quantitative model of feature binding in VSTM that is capable of accounting for various binding phenomena, including that of "illusory conjunction" (Treisman \& Schmidt, 1982). Future work should test the assumption of decisional separability made here (Soto et al., 2014), extend the investigation to GRT reaction time measures (Ashby, 2000; Townsend, Houpt, \& Silbert, 2012), and make contact with other computational approaches to binding and memory (Ashby et al., 1996; Bays et al., 2011; Fitousi, 2013).

Acknowledgments I would like to thank Dr. Noah Silbert and an Anonymous Reviewer for their insightfull comments on anearlier version of this article.

\section{References}

Akaike, H. (1983). Information measures and model selection.-Bulletin of the International Statistical Institute, 50, 277-290.

Algom, D. (2016). Variations on the theme of independence: Tasks and effects of Stroop, Garner, and Townsend. In J. W. Houpt \& L. M. Blaha (Eds.), Mathematical models of perception and cognition. Vol. I (pp. 171-196). New York: Routledge.

Algom, D., \& Fitousi, D. (2016). Half a century of research on Garner interference and the separability - integrality distinction. Psychological Bulletin, 142, 1352-1383.

Allen, R. J., Baddeley, A. D., \& Hitch, G. J. (2006). Is the binding of visual features in working memory resource-demanding? Journal of Experimental Psychology: General, 135(2), 298-313.

Ashby, F. G. (2000). A stochastic version of general recognition theory. Journal of Mathematical Psychology, 44(2), 310-329.

Ashby, F. G., \& Lee, W. W. (1991). Predicting similarity and categorization from identification. Journal of Experimental Psychology: General, 120, 150-172.

Ashby, F. G., \& Townsend, J. T. (1986). Varieties of perceptual independence. Psychological Review, 93(2), 154-179.

Ashby, F. G., Prinzmetal, W., Ivry, R., \& Maddox, W. T. (1996). A formal theory of feature binding in object perception. Psychological Review, 103, 165-192.

Bays, P. M., Wu, E. Y., \& Husain, M. (2011). Storage and binding of object features in visual working memory. Neuropsychologia, 49, 1622-1631.
Cowan, N. (2001). The magical number 4 in short-term memory: a reconsideration of mental storage capacity. The Behavioral and brain sciences, 24, 87-114.

Fitousi, D. (2013). Mutual information, perceptual independence, and holistic face perception.Attention. Perception \& Psychophysics, $75,983-1000$.

Fitousi, D. (2014). On the internal representation of numerical magnitude and physical size. Experimental Psychology, 61, 149-163.

Fitousi, D. (2017a). What's in a "face file"? Feature binding with facial identity, emotion, and gaze direction. Psychological Research. In press.

Fitousi, D. (2017b). Binding sex, age, and race in unfamiliar faces: The formation of "face files". Journal of Experimental Social Psychology, 71, 1-15.

Green, D. M., \& Swets, J. A. (1966). Signal detection theory and psychophysics. New York, NY: Wiley.

Hommel, B. (1998). Event files: Evidence for automatic integration of stimulus-response episodes. Visual Cognition, 5, 183-216.

Hubel, D. H., \& Wiesel, T. N. (1977). Ferrier lecture: Functional architecture of macaque monkey visual cortex. Proceedings of the Royal Society of London B: Biological Sciences, 198(1130), 1-59.

Kahneman, D., Treisman, A., \& Gibbs, B. J. (1992). The reviewing of object files: Object-specific integration of information. Cognitive Psychology, 24, 174-219.

Luck, S. J., \& Vogel, E. K. (1997). The capacity of visual working memory for features and conjunctions. Nature, 390(6657), 279-281.

Makovski, T., \& Jiang, Y. V. (2009). Feature binding in attentive tracking of distinct objects. Visual cognition, 17, 180-194.

Silbert, N. H., \& Hawkins, R. X. D. (2016). A tutorial on General Recognition Theory. Journal of Mathematical Psychology, 73, 94-109.

Silbert, N. H., \& Thomas, R. D. (2013). Decisional separability, model identification, and statistical inference in the general recognition theory framework. Psychonomic Bulletin \& Review, 20, 1-20.

Silbert, N. H., \& Thomas, R. D. (2014). Optimal response selection and decisional separability in Gaussian general recognition theory. Journal of Mathematical Psychology, 60, 72-81.

Singer, W., \& Gray, C. M. (1995). Visual feature integration and the temporal correlation hypothesis. Annual Review of Neuroscience, 18(1), 555-586.

Soto, F. A., Vucovich, L., Musgrave, R., \& Ashby, F. G. (2014). General recognition theory with individual differences: A new method for examining perceptual and decisional interactions with an application to face perception. Psychonomic Bulletin and Review, 22(1), 88111.

Thomas, R. D. (1996). Separability and independence of dimensions within the same-different judgment task. Journal of Mathematical Psychology, 40, 318-341.

Thomas, R. D. (2001). Perceptual interactions of facial dimensions in speeded classification and identification. Perception \& Psychophysics, 63, 625-650.

Townsend, J. T., Hu, G. G., \& Ashby, F. G. (1981). A test of visual feature sampling independence with orthogonal straight lines. Psychological Research, 43, 259-275.

Townsend, J. T., Houpt, J. W., \& Silbert, N. H. (2012). General recognition theory extended to include response times: Predictions for a class of parallel systems. Journal of Mathematical Psychology, 56, 476-494.

Treisman, A. (1996). The binding problem. Current Opinion in Neurobiology, 6(2), 171-178.

Treisman, A. M., \& Gelade, G. (1980). A feature-integration theory of attention. Cognitive Psychology, 12(1), 97-136.

Treisman, A., \& Schmidt, H. (1982). Illusory conjunctions in the perception of objects. Cognitive Psychology, 14(1), 107-141.

Von der Malsburg, C. (1999). The what and why of binding: The modeler's perspective. Neuron, 24(1), 95-104. 
Wenger, M. J., \& Ingvalson, E. M. (2002). A decisional component of holistic encoding. Journal of Experimental Psychology: Learning, Memory, \& Cognition, 28, 872-892.
Wheeler, M. E., \& Treisman, A. M. (2002). Binding in short-term visual memory. Journal of Experimental Psychology: General, 131(1), 48-64. 